\title{
LURR's Twenty Years and its Perspective
}

\author{
Xiang-Chu Yin, ${ }^{1,2}$ Lang-Ping Zhang, ${ }^{2}$ Hui-Hui Zhang, ${ }^{2}$ Can Yin, ${ }^{3}$ \\ Yucang Wang, ${ }^{2,3}$ Yongxian Zhang, ${ }^{2,4}$ Keyin Peng, ${ }^{2,4}$ Haitao Wang, ${ }^{2,5}$ \\ Zhiping Song, ${ }^{2,6}$ Huaizhong Yu, ${ }^{2}$ and Jiancang Zhuang ${ }^{2,7}$
}

\begin{abstract}
Seismogenic process is a nonlinear and irreversible one, so that the response to loading of a seismogenic zone is different from the unloading one. This difference reflects quantitatively the process of an earthquake preparation. A physics-based new parameter-Load/Unload Response Ratio (LURR) was proposed to measure quantitatively the proximity to a strong earthquake and then used to be an earthquake predictor. In the present paper, a brief history of LURR is recalled; inspection of real earthquake cases, numerical simulations and laboratory studies of LURR, prediction efforts in terms of LURR, probability problem of LURR and its prospect are also expatiated.
\end{abstract}

Key words: Load-Unload Response Ratio (LURR), earthquake prediction, numerical simulation, laboratory study.

\section{Introduction}

The idea of LURR (Load/Unload Response Ratio) came as a brainstorm in 1984, twenty years ago, when the first author was a visiting professor in Saint Louis University in U.S.A. cooperating with Professor Otto Nuttli, who was extremely interested in LURR and encouraged us to strive for the maximum achievement. He is many years deceased, however we still deeply miss him.

The essence of an earthquake, from the viewpoint of mechanics or physics, is precisely the failure or instability of the focal media accompanied by a rapid release

\footnotetext{
${ }^{1}$ China Earthquake Administration (CEA), Institute of Earthquake Science, Beijing 100036, China. E-mail: xcyin@public.bta.net.cn

${ }^{2}$ LNM (State Key Laboratory of Nonlinear Mechanics), Institute of Mechanics, Chinese Academy Sciences (CAS), Beijing 100080, China.

${ }^{3}$ ESSCC, University of Queensland, The University of Queensland St. Lucia, Brisbane, QLD 4072, Australia. E-mail: wangyc@esscc.earth.uq.edu.au; canyon@esscc.earth.uq.edu.au

${ }^{4}$ China Earthquake Network Center, CEA, Beijing 100036, China.

5 Xinjiang Earthquake Bureau, CEA, Urumchi 830011, China.

${ }^{6}$ Shanghai Earthquake Bureau, CEA, Shanghai 200062, China.

${ }^{7}$ Department of Earth and Space Sciences, University of California, Los Angeles, CA 90095-1567. E-mail: zhuang@moho.ess.ucla.edu
} 
of energy. Therefore the preparation process of an earthquake is exactly the damage process of the focal media that is usually a narrow layer of rock.

From the microscopic viewpoint, the damage process for geo-material (rock) has incredible richness in complexity (MEAKIN, 1991; BAI et al., 1994; KraJCINNOviC, 1996; XIA et al., 2002). In any rock block there must be a large number of disordered defects (cracks, fissures, joints, faults; caves) with different sizes, shapes and orientations. The damage process includes initiation, growth, interaction, coalition and cascade of cracks. It is an irreversible, far-from -equilibrium and nonlinear process, which has been intensively studied for decades but many fundamental questions remain unsolved. The inherent difficulty of earthquake prediction stems mainly from this complexity. From the macroscopic viewpoint the constitutive curve is a comprehensive description of the mechanical behaviors of the materials. A typical constitutive curve for focal media (rock) is shown in Figure 1. For generality, in Figure 1 the ordinate denotes general load $P$ instead of stress $\sigma$ and the abscissa is the general response $R$ to load instead of strain $\varepsilon$. If the load acting on the material increases monotonously, the material will experience the regimes of elastic, damage and failure or destabilization. The most essential characteristic of the elastic regime is its reversibility; i.e., the positive process and the contrary process are reversible. In other words, the loading modulus and the unloading one are equal to each other. Contrary to the elastic regime, the damage regime is irreversible and the unloading response is different from the loading response, or the loading modulus is different from the unloading modulus. This difference indicates the deterioration of material due to damage.

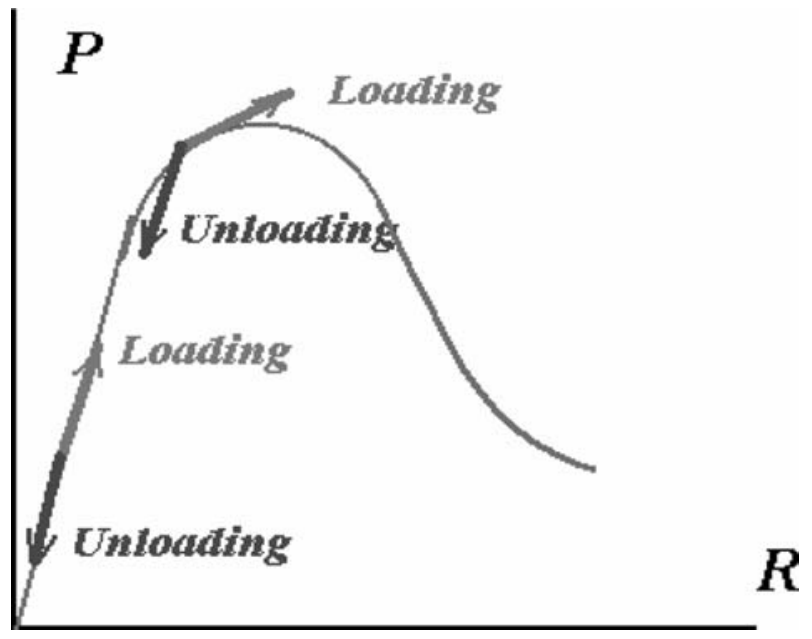

Figure 1

The constitutive curve of focal zone. 
In order to measure quantitatively the difference, two parameters are defined as follows:

The first one is the response rate $X$ defined as

$$
X=\lim _{\Delta P \rightarrow 0} \frac{\Delta R}{\Delta P}
$$

where $\Delta P$ and $\Delta R=$ denote the increments of load $P$ and response $R$, respectively.

The second one is the Load/Unload Response Ratio (LURR) $Y$ defined as

$$
Y=\frac{X_{+}}{X_{-}}
$$

where $X_{+}$and $X_{-}$refer to response rate under loading and unloading condition, respectively.

It is clear that $Y=1$ for the elastic regime since $X_{+}=X_{-}$and $Y>1$ for the damage regime due to $X_{+}>X_{-}$. The more severely the material is damaged, the larger the $Y$ value will be. As the media approach failure the $Y$ value becomes increasingly larger. Therefore the $Y$ value (LURR) could measure the proximity to failure and also act as a precursor for earthquake prediction/forecasting.

In continuum damage mechanics, the damage degree of material is measured by damage variable or damage parameter $d$. There are many ways to define $d$-from scalar to high order tensor (KRAJCINNOVIC, 1996). A direct way is to define $d$ as the relative variation of the effective stiffness tensor. But for a simple condition, it can be simplified. According to Lemaitre's definition (Lemaitre, 1984), the damage parameter $d$ is defined as:

$$
d=\left(E_{0}-E\right) / E_{0}
$$

where modulus $E_{0}$ denotes the Young's modulus for the undamaged original material and $E$ means the Young's modulus in the damaged state for the uniaxial tension or compression.

In fact, the reduction of modulus is due to the existence of defects (cracks, fissures, joints, faults; caves) in the material. Many scientists have studied the relation between modulus and the contained cracks. According to ODA (1983), the increase of the compliance tensor $\boldsymbol{M}$ (the reciprocal of stiffness and $\varepsilon_{i j}=M_{i j k l} \sigma_{k l}$ ) could be expressed as

$$
M_{i j k l}-M_{i j k l}^{o}=(\Delta / 4)\left(\delta_{i l} F_{j k}+\delta_{j l} F_{i k}+\delta_{j k} F_{i l}+\delta_{i k} F_{j l}\right)
$$

where $M_{i j k l}^{o}$ denotes the compliance tensor of the undamaged medium, $M_{i j k l}$ denotes the compliance tensor of the damaged medium, $\delta_{i j}$ is the Kronecker delta, and $F_{i j}$ are the components of the fabric tensor which are defined as 


$$
F_{i j}=\frac{\pi N}{V} \int_{0}^{\infty} \int_{\Omega} a^{3} D\left(n_{k}, a\right) n_{i} n_{j} d \Omega d a,
$$

where $a$ is the size of crack, $D$ is a crack distribution density function, $n$ denotes the unit normal vector and $d \Omega$ is the spherical surface element.

Obviously not only the calculation of the fabric tensor is very complicated, but also it is more difficult to obtain enough data for calculating $F_{i j}$ at present. It is known that a crack or seismic fault with size $a$ corresponds to an earthquake with specified magnitude and energy release (KANAMORI and ANDERSON, 1975). Therefore it would be better to define the $Y$ value directly by the released seismic energy in seismology or $A E$ energy in laboratory as follows

$$
Y=\frac{\left(\sum_{i=1}^{N^{+}} E_{i}^{m}\right)_{+}}{\left(\sum_{i=1}^{N^{-}} E_{i}^{m}\right)_{-}}
$$

where $E$ denotes radiated energy which can be calculated according to the Gutenberg-Richter formula (KANAMORI and ANDERSON, 1975), the sign "+ " means loading and "-" unloading, $m=0$ or $1 / 3$ or $1 / 2$ or $2 / 3$ or 1 . When $m=1, E^{m}$ is exactly the energy itself; $m=1 / 2, E^{m}$ denotes the Benioff strain; $m=1 / 3,2 / 3, E^{m}$ represents the linear scale or area scale of the focal zone respectively; $m=0, Y$ is equal to $N^{+} / N^{-}$, where $N^{+}$and $N^{-}$denote the number of earthquakes which occurred during the loading and unloading duration, respectively. We adopted $m=$ $1 / 2$ in this paper.

In order to predict earthquakes in terms of LURR, some problems should be solved. The first one is how to load and unload the crustal blocks with sizes of hundreds and even thousands of kilometers. One of the means to load and unload the crustal blocks is by the earth tide. Tidal forces exerted by the Moon and Sun produce continuously varying stresses in the earth's crust. How to calculate the tide induced stress in the crust has been elucidated in many works (MELCHIER, 1978; YIN, 1987, 1993; YIN and YIN, 1991; YIN et al., 1994a,b; 1995, 2000; MARUYAMA, 1993).

The second problem is the criteria to judge loading and unloading. We adopt the Coulomb failure hypothesis to judge loading or unloading according to the sign of the increment of Coulomb failure stress which was denoted by CFS in recent literatures (e.g., Harris, 1998, 2000; ReAsenberg and Simpson, 1992).

$$
C F S=\tau_{n}+f \sigma_{n}
$$

where $f, \tau_{n}$ and $\sigma_{n}$ stand for inner frictional coefficient, shear stress and normal stress (positive in tension), respectively, $\mathbf{n}$ is the normal of the fault plane on which the CFS 
reaches its maximum. $\triangle C F S$ denotes the increment of $C F S$. If $\triangle C F S>0$, it is referred to as loading; otherwise $\triangle C F S<0$ is referred to as unloading.

It is well known that the resultant stress $\sigma_{i j}$ in the crust consists of tectonic stress $\sigma_{i j}^{T}$ and the tide induced stress $\sigma_{i j}^{t}$. Since the level of $\sigma_{i j}^{T}$ in the crust (in the order of $\left.10^{6}-10^{8} \mathrm{~Pa}\right)$ is considerably higher than the level of $\sigma_{i j}^{t}\left(10^{3}-10^{4} \mathrm{~Pa}\right)$, the directions of the principle stress of the crust resultant stress and then also the direction of $\mathbf{n}$ can be determined by the tectonic stress only. However, the change rate of tidal-induced stress is much larger than the change rate of the tectonic stress (VIDALI et al., 1998) so $\triangle C F S$ is mainly due to tidal-induced stress that could be calculated precisely. The calculation of elastic deformation of the earth can be formulated as a system of six differential equations of first order. Following and improving MolodensksyTAKEUCHI's work, we calculate the tide-induced stress components of any section in the crust in terms of the Runge-Kutta numerical method ( MELCHIOR, 1978; YIN and YIN, 1991). The shear and normal stress on the fault plane with normal $\mathbf{n}$ can be obtained by stress tensor transform after which the CFS can be calculated easily according to Eq. (7).

\section{Inspection of Real Earthquake Cases}

The retrospective inspections of hundreds of earthquake cases have validated the LURR method (YIN et al., 1995, 2000). For more than $80 \%$ of examined cases the $Y$ value fluctuates around 1 during the early stage of the seismogenic process and it rises when the region approaches the onset of a strong earthquake. Then $Y$ reaches its maximum (significantly larger than 1), but decreases sharply at the eve of the main shock (Figs. 4 and 5). In contrast, we selected seven "stable" regions with low seismicity (no earthquakes with $M \geq 4$ occurred in the examined period) on the Chinese mainland and analyzed the variation in $Y$ for more than two decades (from 1970 to 1992). For all seven regions, the $Y$ value always fluctuated slightly around 1 during the duration (YIN et al., 1995). These results suggest that LURR is available to be a precursor of strong earthquakes.

Certain numerous parameters are necessary such as the strike direction, dip and slip direction of fault, time window and the size and shape of the spatial window, etc. to calculate the variation of LURR. Unfortunately we did not record all the above parameters completely in our early research due to many reasons such as student floating, computer virus attack and lack of experience, so that even our group now cannot reproduce all the previous results. In view of the above-mentioned facts, we have taken two measures to solve this problem:

(1) automatically recording all the parameters on every chart of $Y(t)$.

(2) setting the scaling relation between radius (the circle region), time window and magnitude based on statistical research (YIN et al., 2002 and ZHANG et al., 2005) as below (Fig. 2) 


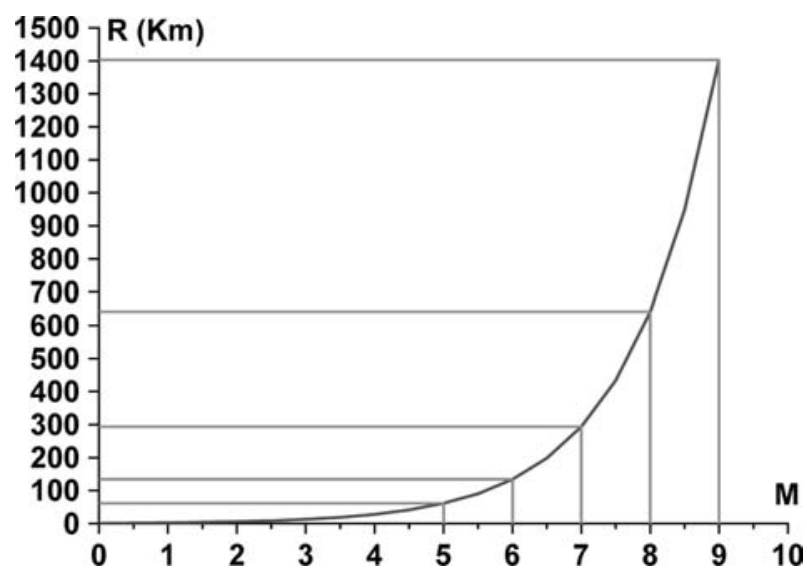

Figure 2

The spatial window size (radius) scale with magnitude.

We often select a circular region as the spatial window in calculating LURR. But in some cases when the epicenters distribute in the forms, which are significantly different from a circular region, we have to select other forms of spatial window as shown in Figure 3.

Figure 4 shows the variation of LURR before some earthquakes with $M \geq 6$ occurred in Southern California, USA and Figure 5 shows the variation of LURR before some earthquakes with $M \geq 7$ occurred on the Chinese Mainland (YIN et al., 1995).

It is well known that the tectonics settings in Southern California, the Chinese Mainland and Japan are significantly different. But the variations of LURR in these regions are similar so that it is suggested that LURR could serve as a precursor of strong earthquakes which occurred in different tectonic settings.

There is a question which was often posed to us: Many scientists have studied the problem of the triggering of earthquakes by the Earth is tide and they found that earthquake occurrence does not correlate well with the Earth's tides (KNOPOFF, 1964; EMTER, 1998; VIDALI et al., 1998). Why were the LURR values in some periods and regions (before a strong earthquake) in our studies considerably larger than 1 (which means in such a situation that earthquake occurrence correlates strongly with the Earth's tides)?

The Earth's crust is not perpetually in a critical state according to the critical point hypothesis (SornetTe and Sornette, 1990; SornetTe and SAmmis, 1995; HuAng et al., 1998; JAUMe and Sykes, 1999; Mora et al., 2000; RundLe et al., 2000). The occurrence of a large earthquake in a region certainly dissipates a sufficient proportion of the accumulated energy and stress and to remove the crust from a critical state so that during the early stage of seismogenic process 

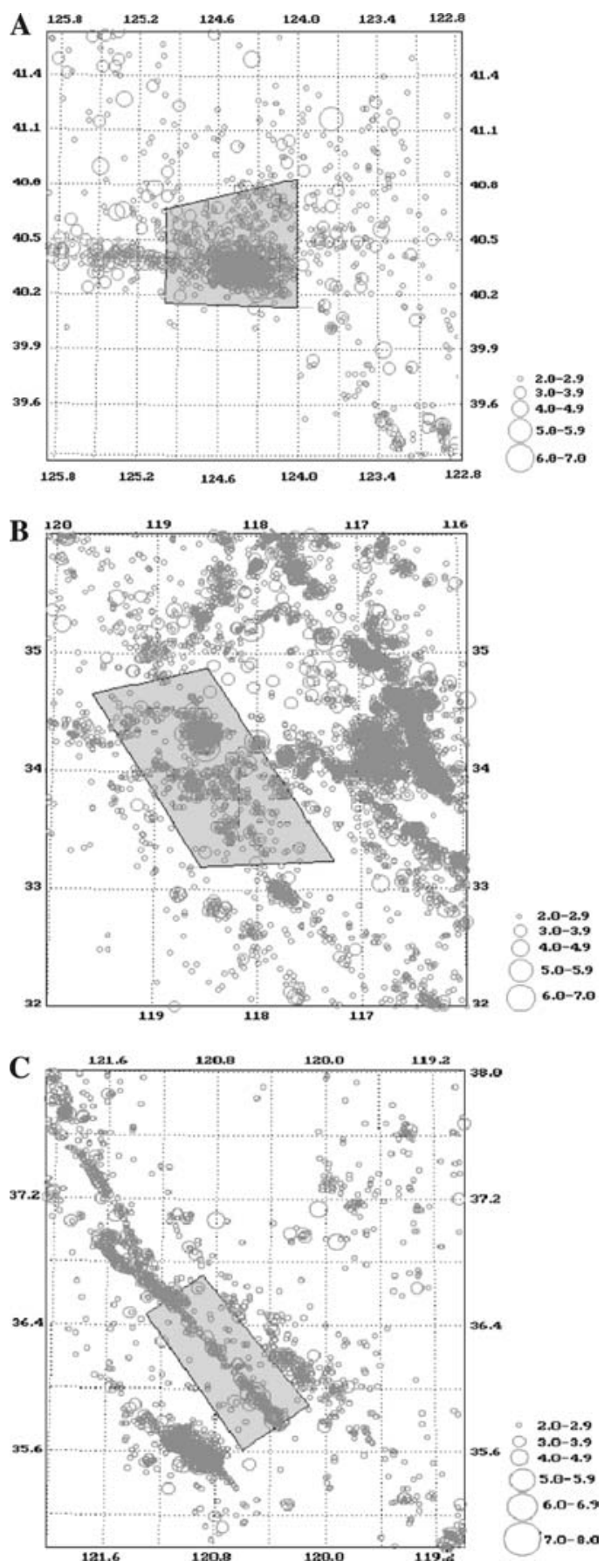

Figure 3

The spatial windows in calculation of LURR for some earthquake cases. 

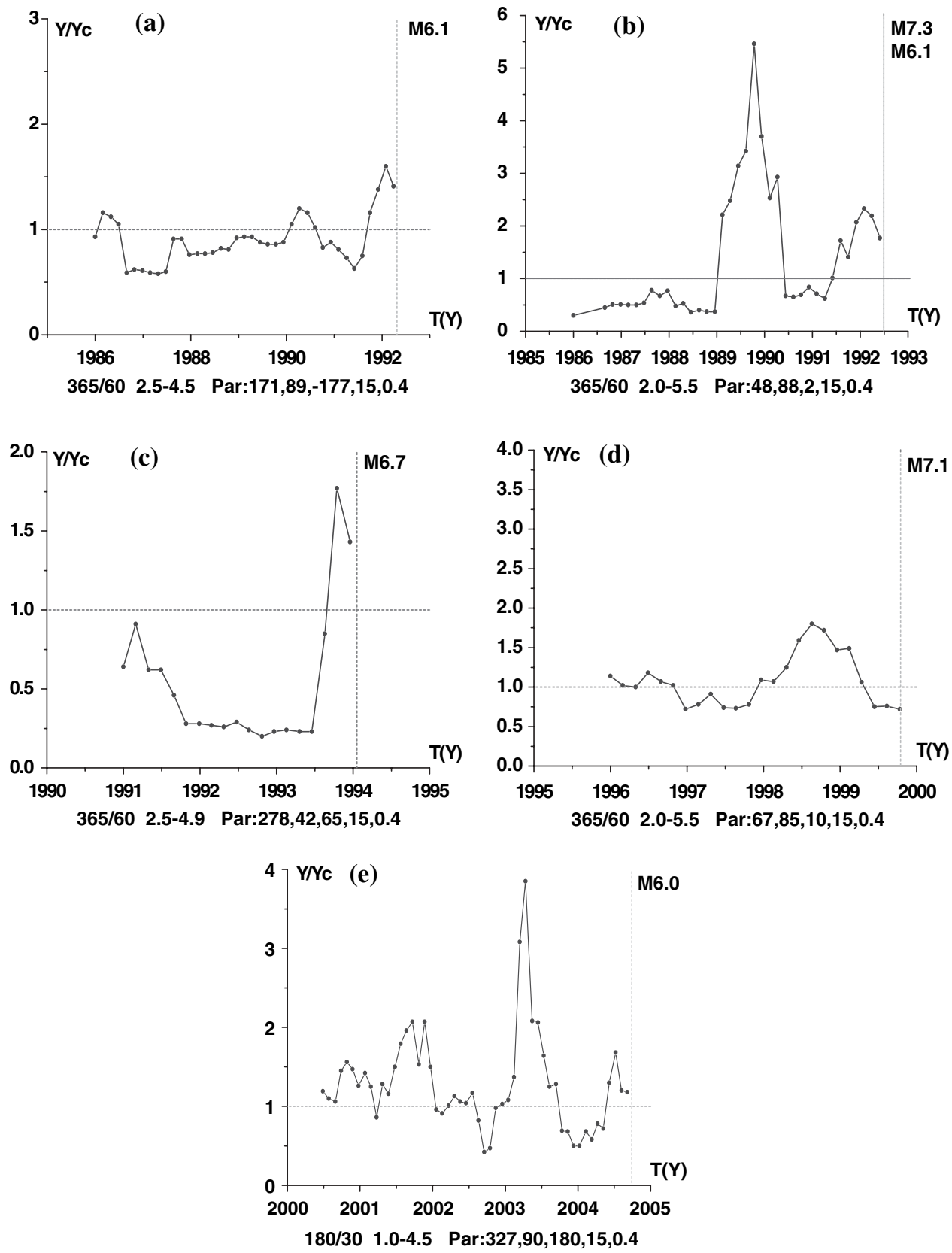

Figure 4

The variation of LURR before earthquakes with $M \geq 6$ occurred in southern California. (a) 1992.4.23, (33.96N,-116.32W), $R=150$. (b) 1992.6 .28 , (34.20N,-116.44W). (c) $1994.1 .17,(34.21 \mathrm{~N},-118.54 \mathrm{E})$. (d) 1999.10.16, (34.59N,-116.27E), $\mathrm{R}=320$. (e) $2004.9 .28,(35.81,-120.365 .9)$. 

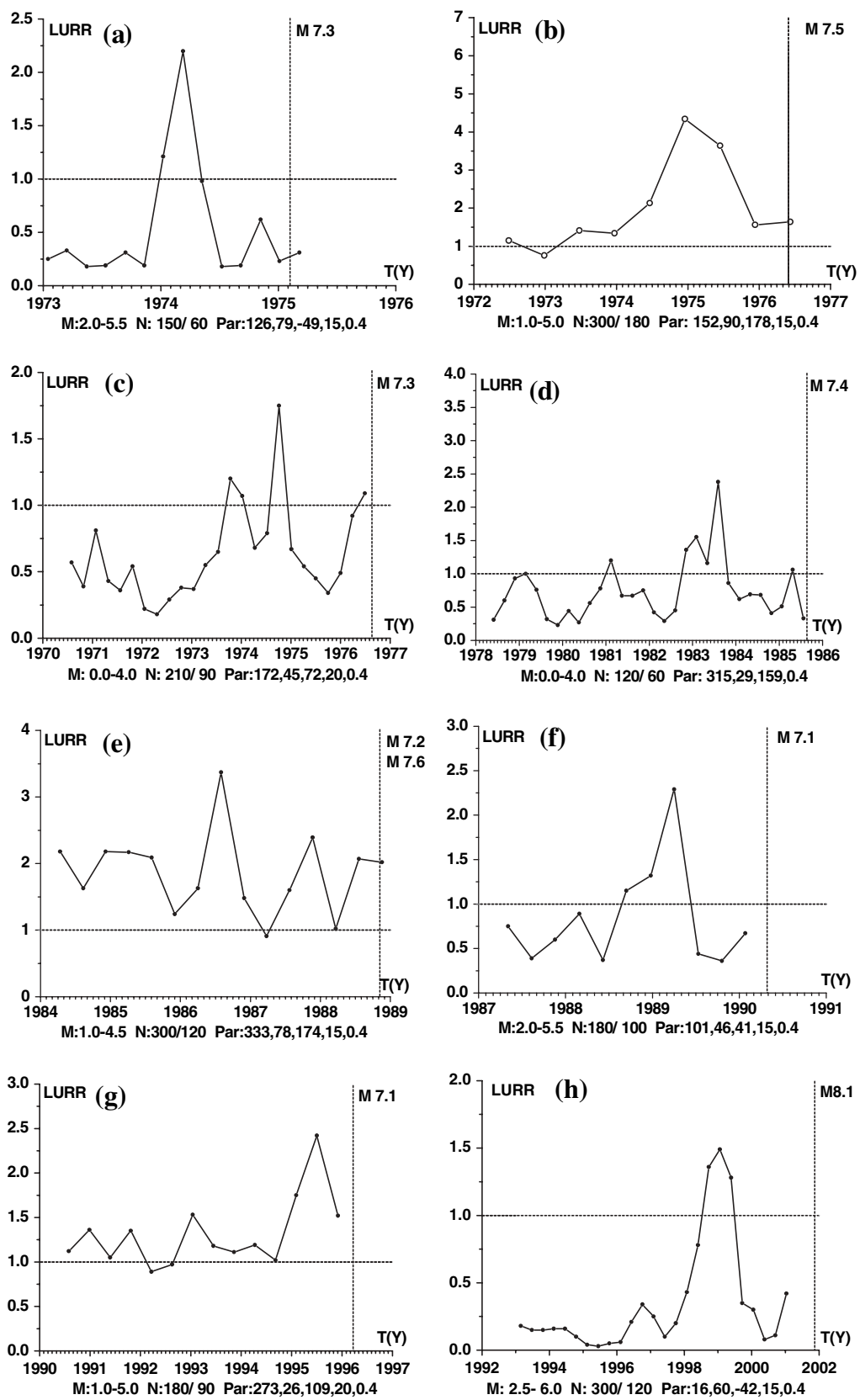

Figure 5

The variation of LURR prior to earthquakes with $M \geq 7$ occurred in the Chinese Mainland. (a) Haicheng Earthquake (1975.2.4). (b) Longling Earthquake (1976.5.29). (c) Songpan Earthquake (1976.8.23). (d) Wuqia Earthquake (1985.8.23). (e) Lancang Earthquake (1988.11.6). (f) Gonghe Earthquake (1990.4.26).

(g) Jiashi Earthquake (1996.3.19). (h) Kunlun Mountain (2001.11.14). 
(a considerably long period after the occurrence of a large earthquake), the tectonic stress level is low and the $Y$ values are usually close to 1 (which means in such situation that earthquake occurrence correlates weakly with the Earth's tides). Subsequently, tectonic loading drives the crust back towards the critical state. During the establishment of criticality, the crust in this region is damaged severely after which the crust will be sensitive to any tiny external disturbance (such as tidal stress). Just in such a condition could the LURR be larger than 1. Figure 6 is a schematic diagram showing this issue. Since high LURR (significantly larger than unity) only exists in a local region (surrounding the epicenter) and a narrow duration (just a relatively short duration prior to the occurrence of strong earthquakes and this duration is only a very small fraction of the entire reoccurrence time between two strong earthquakes), whereas most of the data set for the above investigations on earthquake tidal triggering covers a very long time period which can be comparable to the reoccurrence time and large region which is usually considerably larger than the seismogenic region. Naturally no significant correlation exists between the occurrence of the earthquake and the tidal stress. In other words, the sensitive period only occupies a minute fraction of the entire time window which most scientists used to research the triggering earthquake by

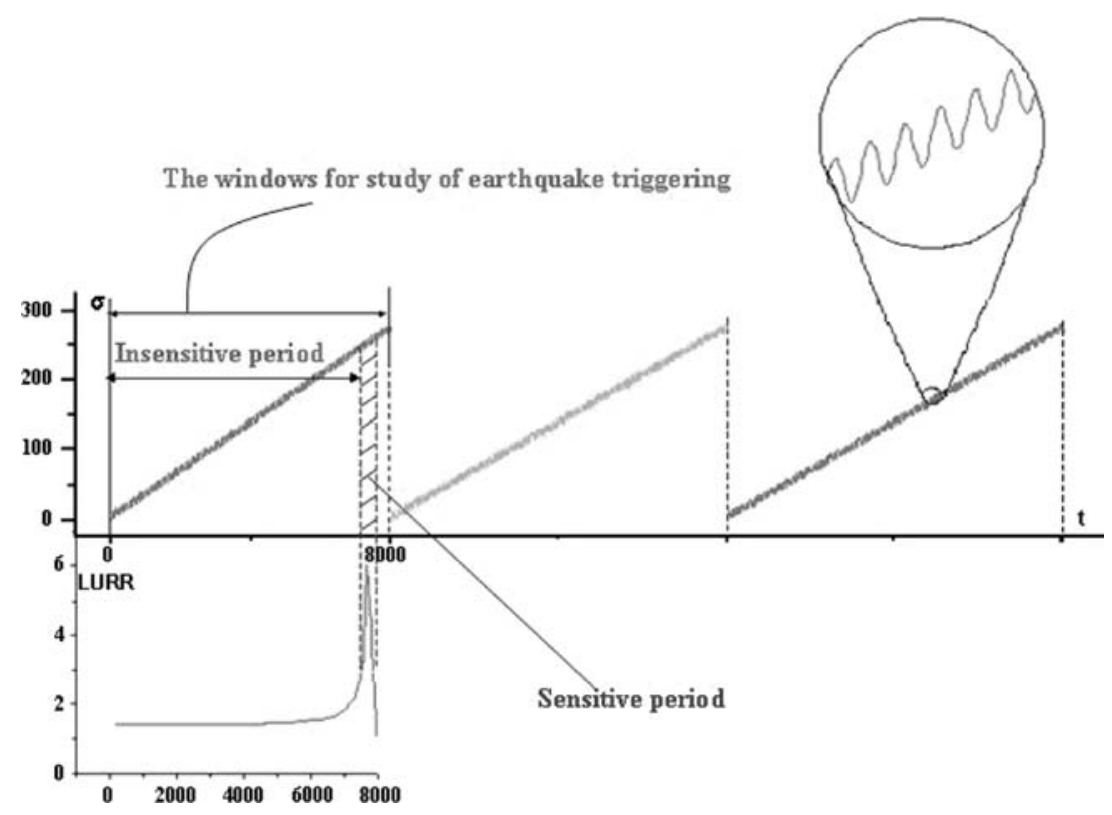

Figure 6

The schematic diagram to illustrate the relation between LURR and the correlation between the occurrence of the earthquake and the tidal stress. 

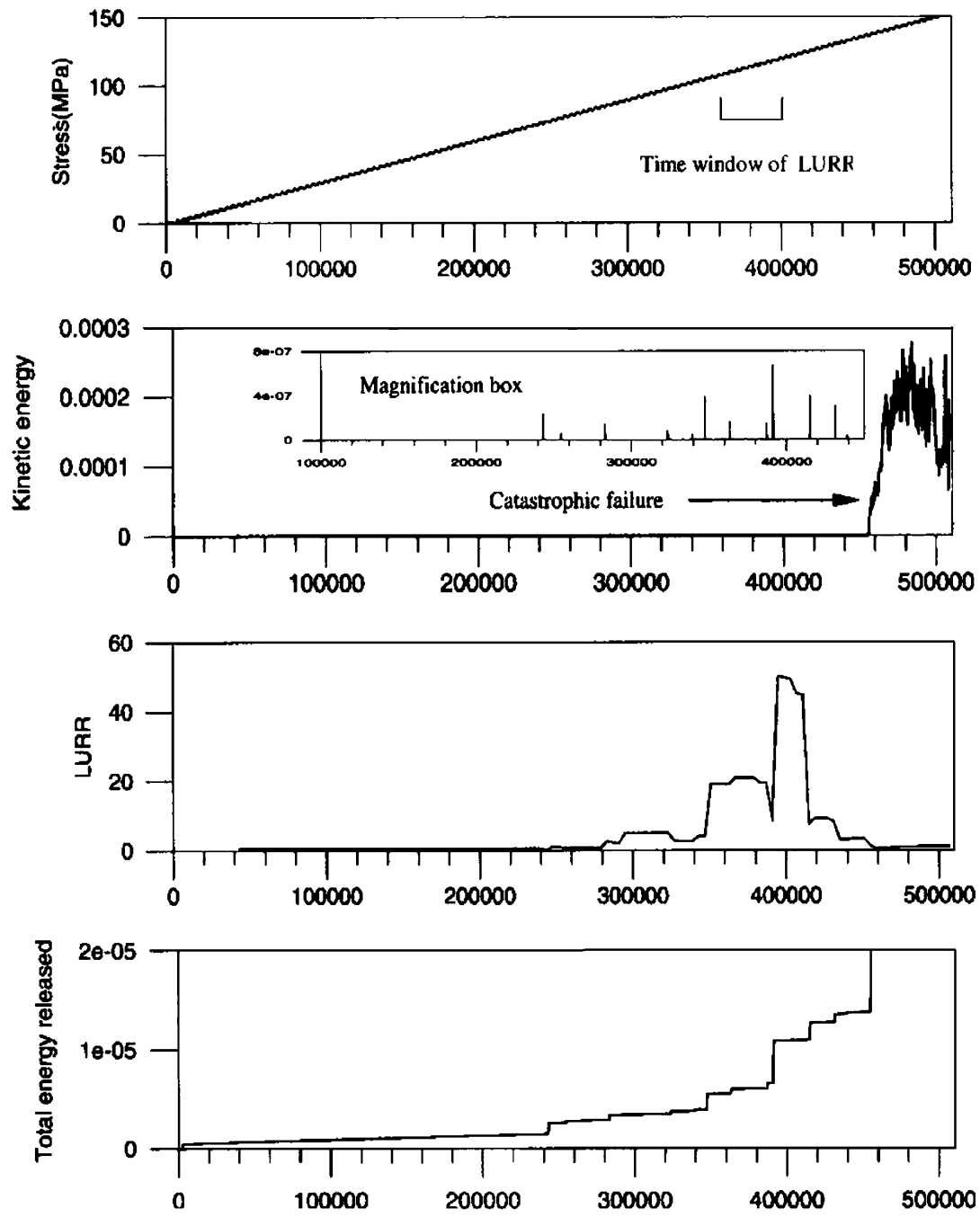

Figure 7

Results of the stress-controlled experiment. From top to bottom, stress measured on the rigid driving plates, kinetic energy within the model, LURR value and cumulative seismic energy release.

tide and the sensitive spatial region is only a slight fraction of the whole region in which most scientists used to research such type of problems.

\section{Numerical Simulation}

There have been numerous numerical simulations on LURR (MORA et al., 2002; WANG et al., 1998b; 1999; 2000; 2004; WANG, 2000) in recent years. The solid lattice 
model, FEM model (RoNG, 2006) and chains network model (LiANG et al., 1996) were used to simulate the evolution of damage and the failure of heterogeneous brittle solid and in the meantime to measure the variation of LURR prior to the macro-fracture similar to the strong natural earthquake.

Figure 7 is after MORA et al.'s paper (2002). The simulating results show that LURR values become high along with the increasing load and then reach their peak point, then drop rapidly prior to the main event. These results reproduce LURR signals similar to those that have often been observed in earthquake prediction practice, and suggest that LURR is correctly identifying the critically sensitive or unstable regime prior to the catastrophe in the model. The conclusions of this paper said: "The results suggest that LURR provides a good predictor for catastrophic failure and motivates further research to study the underlying physical mechanisms. The results provide encouragement for the prospects of earthquake prediction research and the use of advanced simulation models to probe the physics of earthquakes."

In a recent paper (WANG et al., 2004) the statistical tests of LURR have been conducted and come to the conclusion that: "The statistical studies presented in this paper verified statistical robustness."

\section{Laboratory Studies on LURR}

There have also been many laboratory studies on LURR (SHI et al., 1994; YIN et al., 2004; YU, 2004; ZHANG et al., this issue). SHI et al. (1994) conducted laboratory studies on variations of LURR during rock failure in the early 1990s. The results are similar to theory expectations, that is, $Y$ is close to 1 when the stress is small, $Y$ increases when beyond the elastic phase, and $Y$ grows remarkably just before fracture.

In terms of monitoring acoustic emission $(A E)$ in rock mechanics experiments, it is possible to trace the growth of cracks in rock specimens, to observe the damage evolution of the loaded specimens and then to recognize imminent criticality. Therefore significant similarity or overlap exists between the studies of $A E$ and seismology since both disciplines are concerned with the generation and propagation of stress wave, whereas at different geometry scales and over different frenquency ranges. Based on such considerations, we have carried out $A E$ experiments for largescale rock specimens by means of international cooperation among Chinese, Russian, Australian and Japanese scientists in 2001 and 2003, respectively. The detailed descriptions of these experiments have been issued in our papers (KYKCEHKO and YIN, 2003; YIN et al., 2004; ZHANG et al., this issue).

The geometry of specimens is rectangular prisms (Fig. 8) with a maximum size reaching $105 \mathrm{~cm}$ involving four kinds of rocks (granite, gneiss, sandstone and marble). 


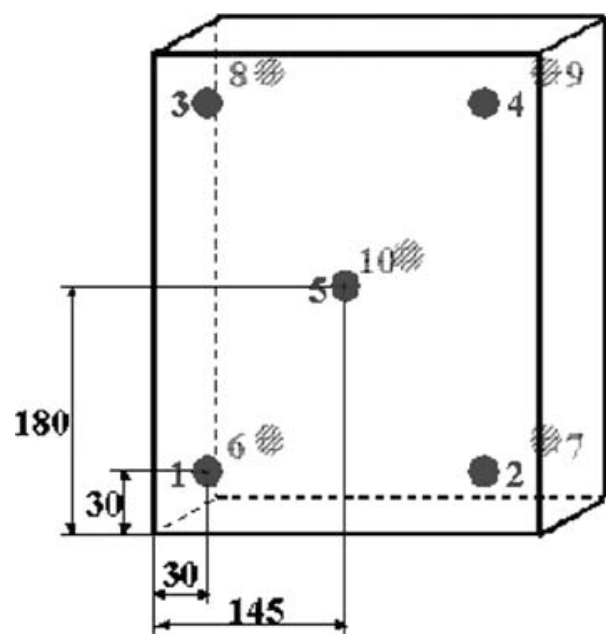

Figure 8

Geometry of the specimens, the loading conditions, and the arrangement of $A E$ sensors.

The specimens are loaded in two directions: the axial stress $\sigma_{1}$ and lateral stress $\sigma_{2}$.

Another principal stress $\sigma_{3}$ is zero so that

$$
\sigma_{1} \neq \sigma_{2} \neq \sigma_{3}
$$

In other words, the stress state is a tri-axial stress state. Under such a stress state most of the specimens undergo shear failure.

In order to simulate the solid Earth tides induced by the Sun and the Moon, the specimens are loaded by the combined action of a constant loading rate, intended to simulate tectonic loading, and a small sinusoidal stress, analogous to the solid Earth tides. The loading history and the typical experimental results are shown in Figure 9. The LURR calculated from the experimental data increases from unity to a high value, and then decreases on the eve of macro-fracture. The experimental results coincide with the seismological observations very well (refer to Figs. 4 and 5).

Here we discuss another question that was also often posed to us: Why the LURR value decreases rapidly on the eve of an earthquake?

According to our understanding, the peak point of LURR indicates the formation of macro-crack in loaded rock specimen (JAEGER and COOK, 1976; RONG, 2006) or the beginning of nucleation of an earthquake (OHNAKA and Kuwahara, 1990; Dieterich, 1992). After that the evolution of the system will develop into the so-called self-driving stage. That means it obeys its own law of evolution and will no longer be sensitive to the external disturbance so that the LURR value decreases rapidly on the eve of an earthquake or catastrophic failure of the specimen. 


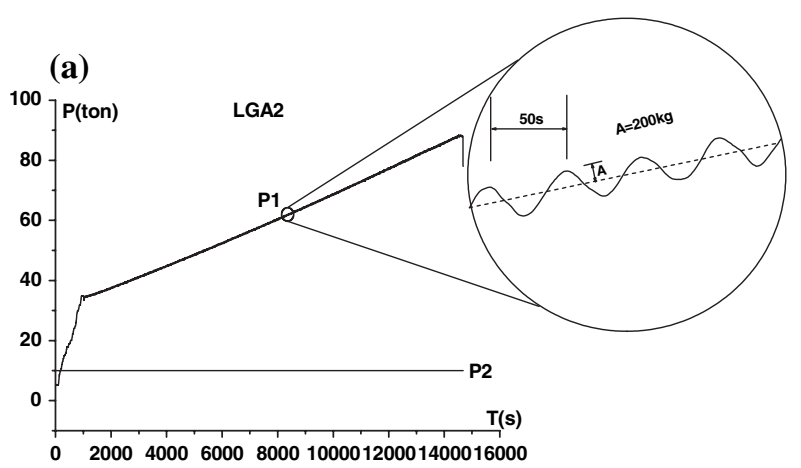

(b)

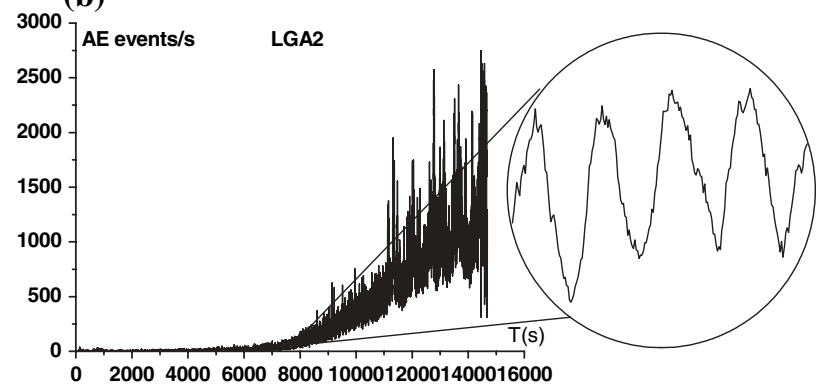

(c)

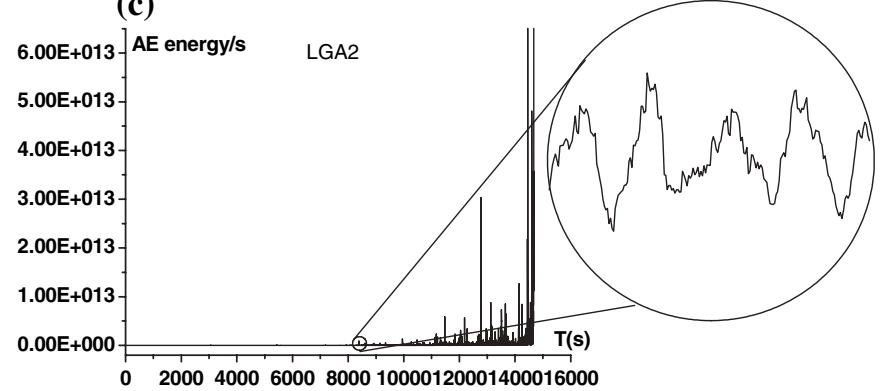

(d)

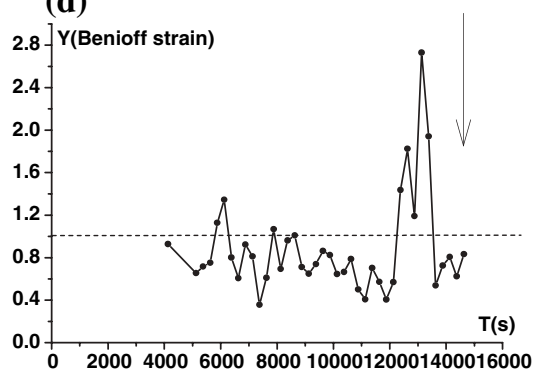

Figure 9

(a) The typical loading history in experiment, (b) the AE rate, (c) the released AE energy per unit time and (d) the variation of LURR during the experimental course. 
Some scientists have researched the phenomenon of critical sensitivity which is close relative to LURR (XIA et al., 2002; XU et al., 2004; ZHANG et al., 2004). The numerical simulation of the damage and fracture process for brittle inhomogeneous material also shows a peak of sensitivity prior to the catastrophic rupture; a phenomenon similar to the variation of LURR (refer to Figs. $2 \mathrm{c}$ and $3 \mathrm{a}$ in ZHANG et al., 2004).

\section{Earthquake Prediction in Terms of LURR}

LURR is easily accepted theoretically, laboratory modeling and numerical simulation also proved its validity, case inspections are satisfactory too. However, LURR theory must be tested ultimately in real earthquake practices. Bearing this in mind, we applied LURR to real earthquake prediction practice. The statistics of earthquake prediction using LURR during the period 1993-1998 is listed in List 1 of the paper (YIN et al., 2000), among the total predicted 18 cases, 12 cases were correct, 6 cases were false (the predicted earthquakes have not occurred) and no missing case (a strong EQ occurred, but no prediction). The successful cases included the 1994 Northridge earthquake and the Kanto earthquake (1996.09.11, Ms 6.6, 35.5 $\mathrm{N}$, $140.9^{\circ} \mathrm{E}$ ) (YIN et al., 1996).

It is encouraging that the prediction results using LURR have been increasingly better. Recently, especially in 2003-2005, we have made a major breakthrough in intermediate-term earthquake forecasting in terms of LURR. Figure 10 is a map

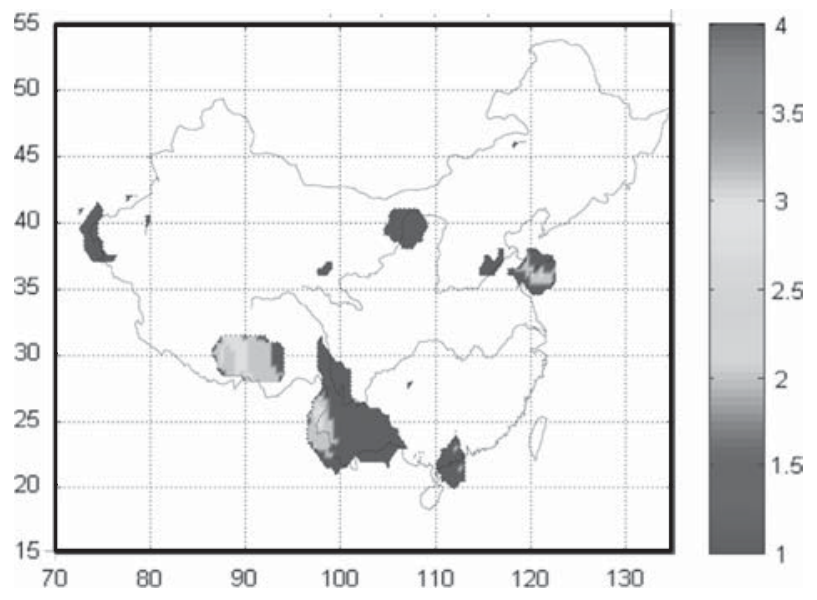

Figure 10

The anomalous LURR regions in the Chinese mainland in 2003 which have a high probability of occurrence for $M \geq 5$ in 2004 . 


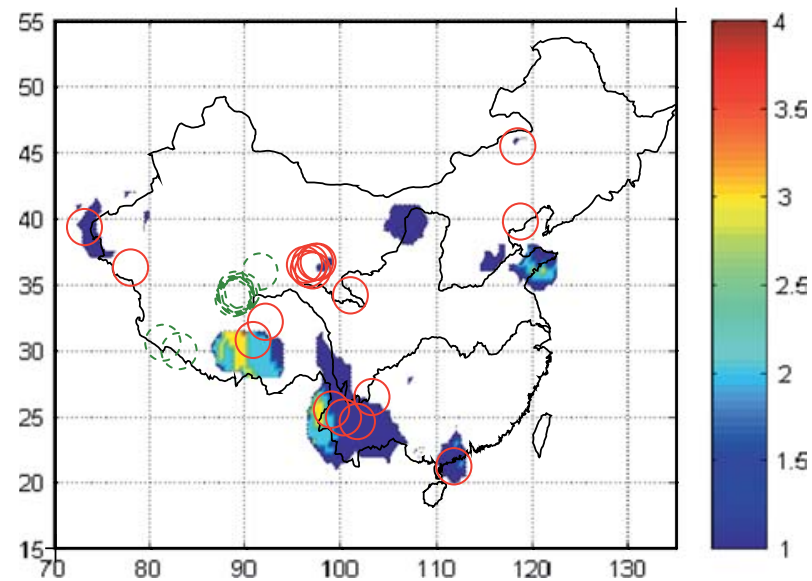

Figure 11

The map of epicenters of earthquakes with magnitude $M \geq 5$ in 2004 in the Chinese mainland. The solid red circles denote the events which occurred in regions in which the observed data were good enough to calculate LURR and the dashed green circles denote the events which occurred in regions where the scarcity of observed data made the LURR calculation impossible.

which shows the anomaly LURR regions in Chinese mainland calculated at the end of 2003. There would be a high probability of occurrence for $M_{s} \geq 5$ earthquakes in the next year (2004) in these regions. This result was issued in the book The Research on Seismic Tendency of China in 2004, edited by the Center for Analysis and Prediction, CSB, pp. 282-285 (YIN et al., 2003) which was issued at the end of 2003 by Seismological Press, Beijing. Figure 11 is a map of epicenters of earthquakes with magnitude $M_{s} \geq 5$ which occurred in the Chinese mainland in 2004. The red solid circles denote the events $M_{s} \geq 5$ (total number 17) which occurred in regions, in which the observed data are available to calculate LURR, and the green dashed circles denote the events $M_{s} \geq 5$ (total number 16) which occurred in regions, where the scarcity of observed data makes the LURR calculation impossible. According to the custom and usage of Chinese seismological circles the earthquakes which occurred in the data scarcity regions should be ignored in the statistics. Therefore there are 15 events among 17 (a percentage of $\mathbf{8 8 \%}$ ) which have fallen into the anomaly LURR regions. In 2005 twelve strong earthquakes with $M \geq 5$ among a total 13 earthquakes (a percentage of 92\%) have fallen into the LURR anomaly regions (Fig. 11) (YIN et al., 2004). The only missing forecasted one-Jiujiang earthquake with magnitude 5.7 (November 26, 2005) is not in the LURR anomaly regions, rather it is located in the data scarcity regions (ZHANG, 2006).

It is worthy to mention the prediction of the Pakistan earthquake with a magnitude of M 7.8 on October 8, 2005. We began to study the seismic trend of the Euro-Asian seismic belt $\left(30^{\circ}-50^{\circ} \mathrm{N}, 30^{\circ}-90^{\circ} \mathrm{E}\right)$ in 2003 . The outcomes were issued in 


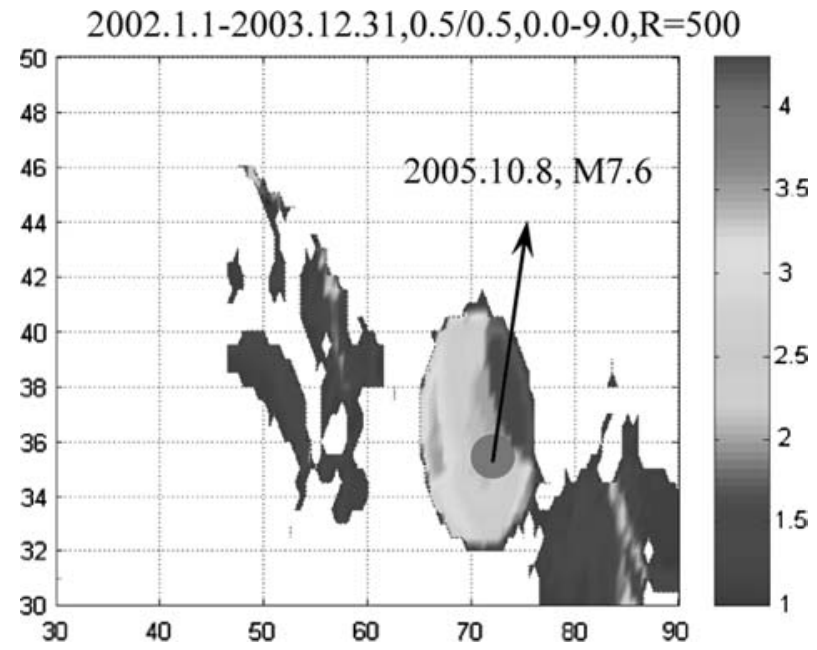

Figure 12

The spatial scanning of LURR in the Europe-Asia earthquake belt in 2002.1.1-2003.12.31.

the Journal Mechanics in Engineering (YIN, 2004) and Supercomputing Newsletter, sponsored by the Computer Network Information Center, Chinese Academy of Sciences. The Pakistan earthquake on October 8, 2005 exactly fell into the High LURR region (Fig. 12).

Recently the spatial scanning of LURR for the western United States $\left(30^{\circ}-50^{\circ} \mathrm{N}, 100^{\circ}-130^{\circ} \mathrm{W}\right)$ also has been conducted (Fig. 13), which shows us the anomalous LURR regions in this region during 2003 (from Jan.1, 2003 to Dec. 31, 2003) and the map of epicenters with magnitude also $M \geq 5$ (circles) observed in 2004. All the observed earthquakes with magnitude $M \geq 5$ fell into the LURR anomalous regions.

Figure 14 shows the maps of LURR anomaly regions from the spatial scanning with different special windows (ZHANG et al., 2005). We have obtained the scaling relations of LURR: The size of seismogenic zone (radius $\mathrm{R}$ of circle area) should scale with the magnitude of the future earthquake (Fig. 2)( YIN et al., 2002a, b)

$$
\log R(\mathrm{~km})=0.087+0.34 \mathrm{M}
$$

and the duration (months) between the peak of LURR and the occurrence time of the future earthquake should also scale with the earthquake magnitude (ZHANG et al., 2005)

$$
\Delta T(\text { month })=60\left(1-2.3 * 10^{-0.08 M}\right) .
$$

According to these scaling relations we predicted the seismic tendency in those regions with high LURR: 


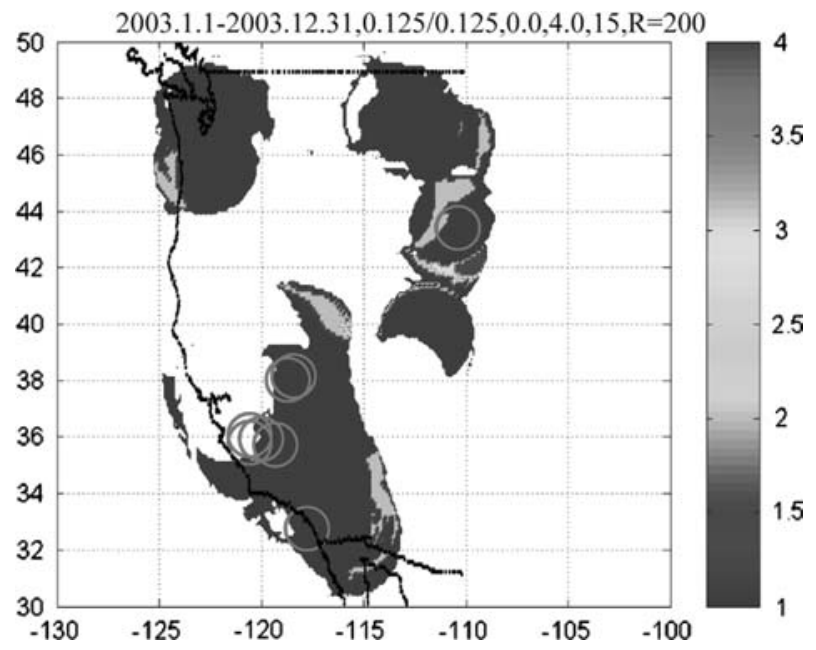

Figure 13

The anomalous LURR regions in the western USA during Jan.1,2003-Dec. 31, 2003 and the map of epicenters with magnitude $M \geq 5$. $\bigcirc$ denotes an earthquake with magnitude $M \geq 5$.

(1) Earthquakes with magnitude around M5 $( \pm 0.5)$ probably occurred in the LURR anomaly regions shown in Figure 14a, especially in the regions before July 31, 2005.

(2) Earthquakes with magnitude around M5.5 $( \pm 0.5)$ probably occurred in the LURR anomaly regions shown in Figure 14b, especially in the region before Dec. 31, 2005.

(3) Earthquakes with magnitude around M6.5 $( \pm 0.5)$ probably occurred in the LURR anomaly regions shown in Figure 14c, especially in the region before Dec. 31, 2006.

(4) Earthquakes with magnitude near M6 $( \pm 0.5)$ probably occurred in the LURR anomaly regions shown in Figure 14d, especially in the region before Dec. 31, 2005.

\section{The Random Distribution of LURR}

The preparation and occurrence process of earthquakes is controlled not only by deterministic dynamical law but also affected by some stochastic or disorder factors. Therefore we have to study the influence of random factors on LURR in order to judge the height to which the $Y$ value reaches can be considered as a precursor under the specified confidence (e.g., 0.90, 0.95 and 0.99) (ZHUANG and YIN, 1999). 

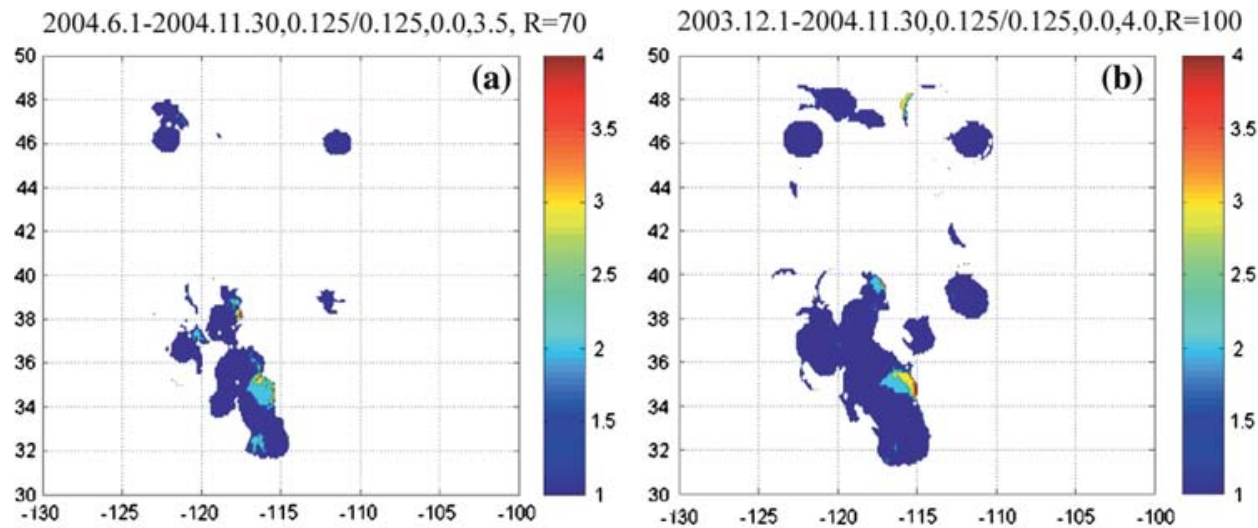

2003.12.1-2004.11.30,0.125/0.125,0.0,4.0, R=200

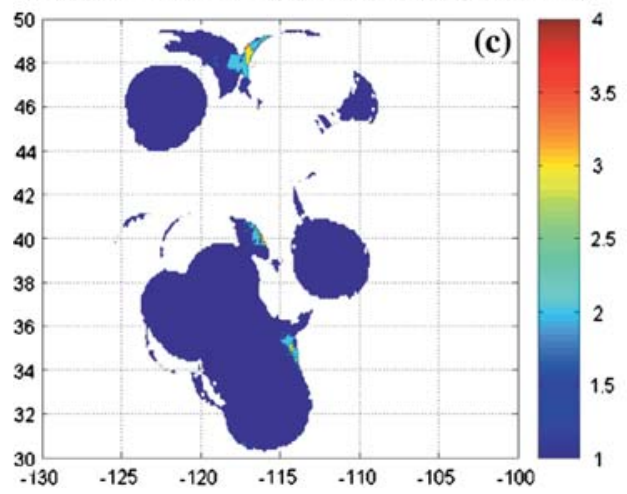

2003.1.1-2003.12.31,0.125/0.125,0.0,4.0,15, R=200

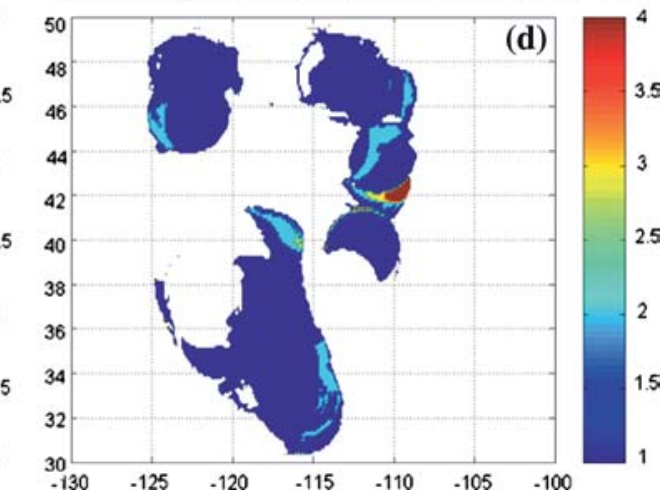

Figure 14

The anomalous LURR regions in the western USA with different special windows. (a) $\mathrm{R}=70 \mathrm{~km}$; (b) $\mathrm{R}=100 \mathrm{~km}$; (c) $\mathrm{R}=200 \mathrm{~km}$; (d) $\mathrm{R}=200 \mathrm{~km}$ with different time windows.

The Poisson model is used to describe the occurrence times of earthquakes. We assume that earthquakes in a region obey the following basic assumption:

1. The earthquakes occur according to a Poisson process with a constant rate $\lambda$. The number of earthquakes occurring in the time interval $[0, T]$ has a Poisson distribution with expectation $\lambda T$, i.e.,

$$
\operatorname{Pr}\{N=n\}=\frac{(\lambda T)^{n}}{n !} e^{-\lambda T}
$$

2. The distribution of the magnitudes obeys the Gutenberg-Richter law, i.e., an exponential distribution with the probability density function.

3. The probabilities of an earthquake falling in a loading period and unloading period are equal, both $1 / 2$. 


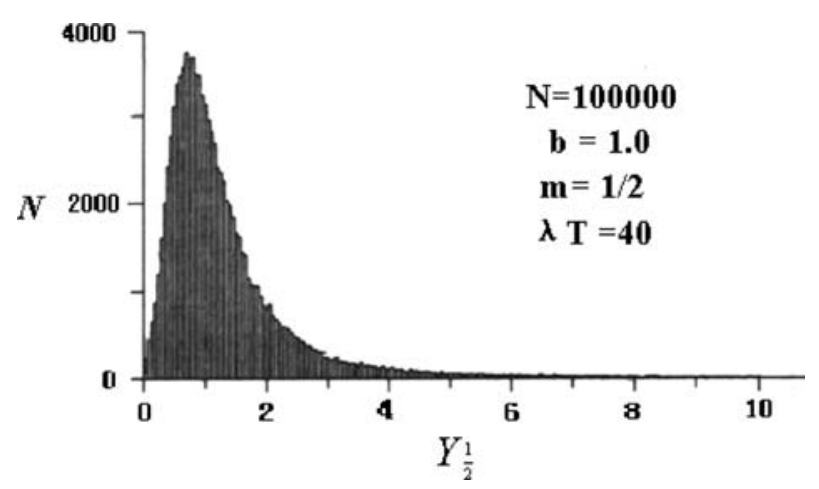

Figure 15

The random distribution of $Y$ under the specified condition.

Based on the above assumptions, a simulation algorithm for computing the distribution and the confidence bands of the LURR is outlined below:

1. For each time interval (assumed as unit time interval), simulate two random variables $P, Q$ belonging to a Poisson distribution of rate $\lambda / 2$, where $\lambda$ is the occurrence rate of earthquakes. $P, Q$ can be regarded as the number of loading earthquakes and unloading earthquakes occurring in the time interval, respectively.

2. According to the given $b$ value, simulate $P$ magnitudes for the loading earthquake and $Q$ magnitudes for the unloading earthquakes.

3. Calculate the $Y$ value.

4. Repeat step 1 to 3 for one million times, and draw the histogram of $Y$ values, which could be regarded as the probability density function (p.d.f) of LURR. Figure 15 shows an example for $b=1, \lambda T=40$ and $m=1 / 2$.

5. Find the $0.90,0.95$ and 0.99 confidence bands from the p.d.f of LURR, respectively. Figure 16 is an example of such kind of simulated results. For example, for the condition: Occurrence rate $=50, b=1, m=1 / 2$, confidence $95 \%, Y$ value should be equal or greater than 2.4 which denoted as $Y_{c}$.

The results show that the variation of LURR is controlled by the occurrence rate for the Poisson model and the parameter $S(S=b / m$, where $b$ is the constant in the Gutenberg-Richter law and $m$ is the power in (6)). The larger the occurrence rate and the $S$ value, the more stable or more concentrated around 1 the $Y$ value is.

Instead of $Y$ the parameter $Y / Y_{c}$ will be used to measure the anomaly of LURR hereafter. It is considered that LURR is an anomaly when $Y / Y_{c}>1$. The larger the value of $Y / Y_{c}$, the greater the possibility of strong earthquakes in the specified region and time window will be. 


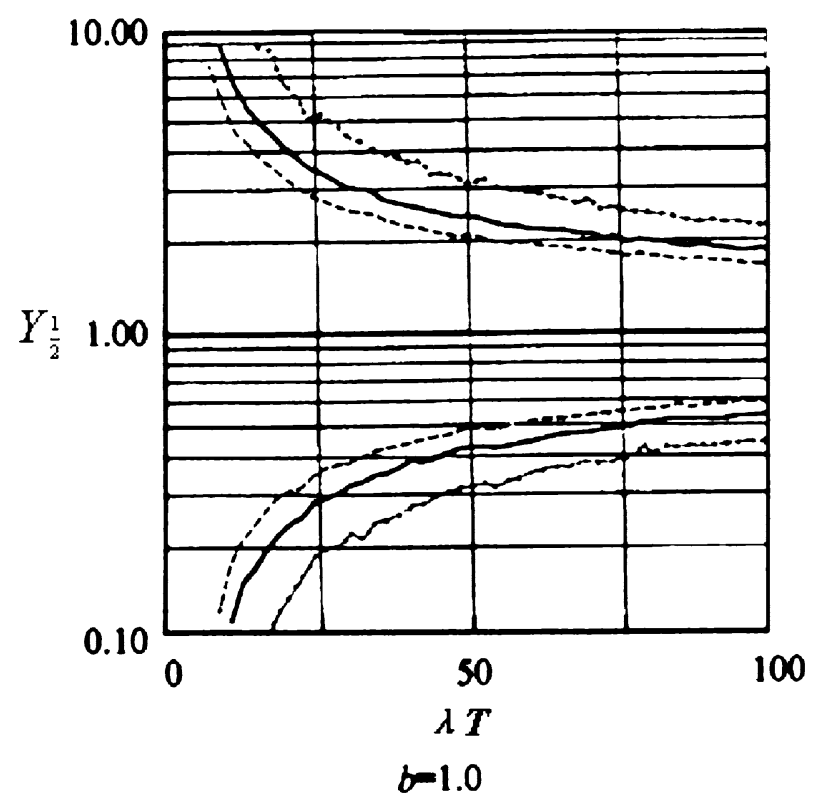

Figure 16

Variation of confidence bands of $Y$ with occurrence rates under the Poisson model.

\section{Perspective}

The LURR has been become a new promising approach to earthquake prediction after twenty years effort and there exits considerable room for improvement and development in it (YIN, 2005; ZHANG, 2006).

As mentioned above, the LURR is a parameter which mirrors the closeness to strong earthquakes and serves as an approach to natural earthquake prediction. It has also been applied to the prediction of reservoir induced earthquakes (CHEN and YIN et al., 1995), mining rock bursts (YIN et al., 2004b) and landslides (XU and HUANG, 1995; JIANG, 2004). It could potentially be used for the prediction of other critical phenomena and the damage evaluation or "healthy-diagnoses" of major engineering structures.

\section{Acknowledgements}

The authors gratefully acknowledge the support from Special Funds for Major State Basic Research Project under Grant Nos.2004 CB418406, NSFC under grant Nos. 10232050, 10572140, the Informatization Construction of Knowledge Innovation Projects of the Chinese Academy of Sciences "Supercomputing Environment Construction and Application" (INF105-SCE-2-02). 
The authors are grateful to many of our teachers, friends, colleagues, leaders and students for their support, encouragement and assistance. They are Qian Xue Sen, Zheng zhe-min, Qin Xin Ling, Bai Yi Long, Mei Shi Rong, Chen Zhang Li, Xia Mengfen, Liang Nai Gang, Ke Fujiu, Chi Xuebin, Li Jie, Keiiti Aki, Leon Knopoff, Peter Mora, Bernard Minster, Dave Jacksen, Takuo Maruyama and Zheng-kang Shen.

\section{REFERENCES}

BAI, Y.L., Lu, C.S., Ke, F.J, et al. (1994), Evolution induced catastrophe, Phys. Lett. A185, 196-201.

Bowman, D.D., Oulllen, G., Sammis, C.G., Sornette, A., and Sornette, D. (1998), An observational test of the critical earthquake concept, J. Geophys. Res. 103, 24,359-24,372.

BAKun, W.H., and Lindh, A.G. (1985), The Parkfield, California, earthquake prediction experiment, Science 229, 619-624.

Chen, J.M., ZhAng, Z.D., and YANG, L.Z. (1994), Seismic abnormalities in LURR of ground water lever, Earthquake 1, 73-78.

CHEN, X.Z. and YIN, X.C. (1995), Application of LURR theory to the earthquake prediction for reservoirinduced earthquakes, Earthquake Research in China 11, 361-367.

Cotton, L. A. (1922), Earthquake frequency, with special reference to tidal stresses in the lithosphere, Bull. Seismol. Soc. Am. 12, 47-198.

Cundall, P.A. and Strack, O.D.L. (1979), A discrete element model for granular assemblies, Geotechnique 29, 47-65.

DIETERICH J.H. (1992), Earthquake nucleation on faults with rate- and state-dependent strength, Tectonophysics 211, 115-134.

Emter, D. (1997), Tidal triggering of earthquakes and volcanic events. In: (WILHELM, H., et al., ed.), Tidal Phenomena (Springer-Verlag 1997), pp. 293-309.

HARRIS, R.A. (1998), Introduction to special section: stress triggers, stress shadows, and implication for seismic hazard, J. Geophys. Res. 103, 24347-24358.

HARRIS, R.A. (2000), Earthquake stress triggers, stress shadows, and seismic hazard, Current Science 79, $1215-1225$.

Huang, Y., Saleur, H., Sammis, C.G. and Sornette, D. (1998), Precursor, aftershocks, criticality and self-organization criticality, Europhys. Lett. 41, 43-48.

Huang, R. and Xu, Q. (1997), Scientific Analysis Principle and Its Applications to Generalized System in Engineering Geology (Geological Press, Beijing 1997) (in Chinese).

JAEGER, J.C. and CoOK, N.G.W., Fundamentals of Rock Mechanics (Chapman and Hall, London, 1976).

JAUME, S.C. and SYKeS, L.R. (1999), Evolving towards a critical point: A review of accelerating seismic moment/energy release prior to large and great earthquakes, Pure Appl. Geophys. 155, 279-306.

JiAnG, T. (2004), The Analysis of landslide in terms of Load/Unload Response Ratio, Ph.D. Thesis, Institute of Geology, Chinese Seismological Bureau (in Chinese).

Kanamori, H. and Anderson, D.L. (1975), Theoretical basis of some empirical relation in seismology, Bull. Seismol. Soc. Am. 65, 1073-1096.

KNOPOFF, L. (1964), Earth tide as a triggering mechanism for earthquakes, Bull Seismol. Soc. Am. 54, 18651870.

Krajcinnovic, D., Damage Mechanics (Elsevier, Amsterdam, 1996).

Күксенко, В.С. and YІм, Х.С (2003), Влияние слабых механических воздействий наповедение очага разрушения, Известия Академии НаҮк, Серия Физическая, moм 67, No. 6c. 877-881 (in Russian).

Lemaitre, J., Formulation and identification of damage kinetic constitutive equations. In Continuum Damage Mechanics (ed. Krajcinnovic, D.) (Springer-Verlag, Wien, New York 1987). 
LiAng, N., LiU, Q., LI, J., and Song, H., A chains net-work model simulating meso- mechanics behavior and micro-damage evolution of in situ reinforced ceramics. In Advanced in Engineering Plasticity and its Applications (eds. Abe, T. and Tsuta, T.) (Pergamon, Amsterdam, 1996), pp. 141-146.

Maruyama, T. (1993), Earthquake Prediction in China, Zisin 19(5), 68-76 (in Japanese).

Melchier, P. The Tide of the Planet Earth, (Pergamon Press, New York 1978).

MeAkin, P. (1991), Model for material failure and deformation, Science 252, 226-234.

Mora, P. and Place, D. (1993), A lattice solid model for the nonlinear dynamics of earthquakes, Int. J. Mod. Phys. C4, 1059-1074.

Mora, P., Place, D., Abe, S., and Jaume, S. (2000), Lattice solid simulation of the physics of faultzones and earthquakes: The model, results and directions. In Geocomplexity and the Physics of Earthquakes (eds. Rundle, J.B., Turcotte, D.L., and Klein, W.) (AGU, Washington 2000), pp. 105125.

Mora, P., Wang, Y., Yin, C., Place, D., and Yin, X.C. (2002), Simulation of Load-Unload Response Ratio and critical sensitivity in the lattice solid model, Pure Appl. Geophys. 159, 2525-2536.

ODA, M. (1983), A method for evaluating the effect of crack geometry on the mechanical behavior of cracked rock mass, Mech. Mater. 2, 163-171.

OHnAKA, M. and Kuwahara, Y. (1990), Characteristic features of local breakdown near a crack-tip in the transition zone from nucleation to unstable rupture during stick-slip shear failure, Tectonophysics 175 , 197-220.

QIANG XU and RuN-QIU HuANG (1995), Investigation on precursor of slope instability in term of LURR, Chinese J. Geolog. Disasters 6, 2-16, (in Chinese).

ReAsenberg, P.A. and Simpson, R.W. (1992), Response of regional seismicity to the static stress change produced by the Loma prieta earthquake, Science 255, 1687-1690.

Roeloffs, E.A. and LAngbein, J. (1994), The earthquake prediction experiment at parkfield, California, Rev. Geophys. 32, 315-336.

Rong, F. (2006), Multiscale Simulation of damage Evolution in Heterogeneous Brittle Media, Ph.D. Thesis of the Graduate School, China Academy Science.

Rundle, J.B. et al. (2000), Precursor seimic activation and critical-point phynomena, Pure Appl. Geophys. $157,2165-2182$.

Shi, X., Xu, H., WAN, Y., Lu, Z., and CHEN, X. (1994), The rock fracture under simulated tide force-Laboratory study on the Loading and Unloading Response Ratio (LURR) theory, Acta Geophysica Sinica 37, 631-636.

Sornette, A. and Sornette, D., (1990), Earthquake rupture as a critical point: Consequences for telluric precursors, Tectonophysics 179, 327-334.

Sornette, D. and Sammis, C. G. (1995), Complex critical exponents from renormalization group theory of earthquake prediction, J. Phys. I. France 5, 607-619.

Vidali, J.E., Agnew, D.C., Johnston, M.J.S., and Oppenheimer, D.H. (1998), Absence of earthquake correlation with earth tides: An indication of high preseismic fault stress rate, J. Geophys. Res. 103, 2456724572.

WAng, H.T., Peng, K.Y., Zhang, Y.X., WAng, Y.C., and YIN, X.C. (1998a), Characters of variation of LURR during the earthquake sequence of Xinjiang, Chinese Sciences Bulletin 43, 1752-1755.

WANG, T.W. (1995), The application of Load/Unload Response Ratio in earthquake prediction by magnetic method, Observation and Research of Seismic Geomagnetism 16, 26-29 (in Chinese).

WANG, Y. C., YIN, X.C., and WANG, H.T. (1998b), The simulation of rock experiment on Load/Unload response for earthquake prediction, Earthquake Research in China 14(2), 126-130.

WANG, Y.C., YIN, X.C., and WANG, H.T. (1999), Numerical simulation on Load/Unload Response Ratio (LURR) theory, Acta Gephysica Sinica 42, 669-676.

Wang, Y.C., Yin, X.C., Ke, F.J., XIA, M.F., and Peng, K.Y. (2000), Simulation of rock failure and earthquake process on mesoscopic scale, Pure Appl. Geophys. 157, 1905-1928.

WANG, Y.C. (2000), Simulation of earthquake process and studies on predictability, Post-Doctor Report, Institute of Mechanics, CAS (in Chinese). 
Wang, Y.C., Mora, P., Yin, C., and Place, D. (2004), Statistical tests of Load-Unload Response Ratio signals by lattice solid model: Implication to tidal triggering and earthquake prediction. Pure Appl. Geophys. 161, 1829-1839.

XIA, M.F, WEI, Y.J., KE, F.J., and BAI, Y.L. (2002), Critical sensitivity and transscale fluctuations in catastrophe rupture, Pure Appl. Geophys. 159(10), 2491-2509.

XU, Q. and HuANG, R.Q. (1995), Investigation on precursor of slope instability in term of LURR, Chinese J. Geological Disasters 6, 2, 1995 (in Chinese).

YANG, L.Z., HE, S.H., and XI, Q.W. (1994), Study on the variation of the property of rock elasticity by Load/Unload Response Ratio of tidal volume strain, Earthquake Research in China 10, 90-94.

YIN, C. (2005), Exploring the Underlying Mechanism of Load/Unload Response Ratio Theory and its Application to Earthquake Prediction, Ph.D. Thesis, The University of Queensland, Australia.

YIN, X.C. (1987), A new approach to earthquake prediction, Earthquake Research in China 3, 1-7 (in Chinese with English abstract).

YIN, X.C. and YIN, C. (1991), The precursor of instability for nonlinear system and its application to earthquake prediction, Science in China 34, 977-986.

YIN , X.C. (1993), A new approach to earthquake prediction (Russia's Nature), 1, 21-27 (in Russian).

YIN, X.C., YIN, C., and CHEN, X.Z. (1994a), The precursor of instability for nonlinear system and its application to earthquake prediction - The Load-Unload Response Ratio theory. In Nonlinear Dynamics and Predictability of Geophysical Phenomena (eds. Newman, W.I., Gabrelov, A. and Turcotte, D.L.) Geophysical Monograph 83, IUGG Volume 18, 55-60.

Yin, X.C., Chen, X.Z., Song, Z.P., and Yin, C. (1994), The Load-Unload Response Ratio theory and its application to earthquake prediction, J. Earthquake Prediction Research 3, 325-333.

Yin, X.C., Chen, X.Z., Song, Z.P., and Yin, C. (1995), A new approach to earthquake prediction: The Load/Unload Response Ratio (LURR) theory, Pure Appl. Geophys. 145, 701-715.

YIN X.C., Song Z.P., and WANG, Y.C. (1996), The temporal variation of LURR in Kanto and other regions of Japan and its application to earthquake prediction, Earthq. Res. in China 10, 381-385.

Yin X.C., Wang Y.C., Peng K.Y., Bai Y.L., Wang H.T., and Yin X.F., (2000), Development of a new approach to earthquake prediction-Load/unload Response Ratio (LURR) theory, Pure Appl. Geophys. 157, 2365-2383.

Yin, X.C., Mora, P., Peng, K.Y., Wang, Y.C., and Weatherly, D. ( 2002a), Load-Unload Response Ratio and accelerating moment/energy release, critical region scaling and earthquake prediction, Pure Appl. Geophys. 159, 2511-2524.

Yin, X.C., Peng, K.Y., Yu, H.Z., Wang, Y.C., Yin, C., and Zhang, Y.X. (2002b), Scaling of LURR Critical Region, 3rd ACES Workshop, May 5-10, 2002, Island of Maui, Hawaii, U.S.A.

Yin, X.C., Yu, H.Z., Kukshenko, V., Xu, Z.Y., Wu, Z.S., Li, M., Peng, K.Y. Elizarov, S., and Li, Q. (2004b), Load-Unload Response ratio (LURR), Accelerating Energy release (AER) and State Vector evolution as precursors to failure of rock specimens, Pure Appl. Geophys 161, 11-12, 2405-2416.

YIN, X.C. (2005), A new approach to earthquake prediction-Load/Unload Response Ratio (LURR) theory, Mechanics in Engineering 26, 1-7, (in Chinese).

YU, H.Z. (2004), Experimental research on precursors of brittle heterogeneous media and earthquake prediction methods, Ph.D. Thesis, Institute of Mechanics, CAS (in Chinese).

Zhang, H.H., Yin, Xiangchu, and Liang Naigang (2005), The spatial variation of LURR and seismic tendency in western United States, Earthquake Research in China 19(3), 338-345.

Zhang H.H. (2006), Prediction of Catastrophic failure in Heterogeneous Brittle Media-Study and Practice of Load/Unload Response Ratio (LURR), Ph.D. Thesis, Graduate School, CAS.

ZHANG, J.H. (1995), The analysis of the geomagnetic abnormalities in Load/Unload Response Ratio method, Observation and Research of Seismic Geomagnetism 16, 61-63 (in Chinese).

Zhang, X.H., Xu, X.H., XIA, M.F., and BAI, Y.L. (2004), Critical sensitivity in driven nonlinear threshold systems, Pure Appl. Geophys. 161, 1931-1944.

Zhang Yongxian and Xiangchu Yin (2004), LURR and the San Simeon M6.5 earthquake in 2003 and the seismic tendency in California, The 4th ACES Workshop, July 9-14, 2004, Beijing China.

ZHEN, X. P. (1996), Earthquake and Load/Unload Response Ratio of terrestrial magnetic field to solar wind, Observation and Research of Seismic Geomagnetism 17, 49-53 (in Chinese). 
ZhuAng, J.C. and Yin, X.C. (1999), Random distribution of the Load/Unload Response Ratio (LURR) under assumptions of poisson model, Earthquake Research in China 15, 128-138.

(Received November 11, 2004, revised October 10, 2005, accepted December 1, 2005)

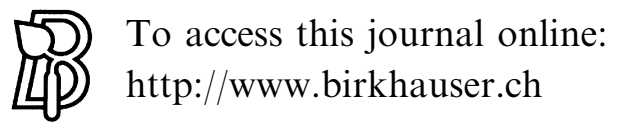

